\title{
Inflammatory cells and activation markers in BAL during acute rejection and infection in lung transplant recipients: a prospective, longitudinal study
}

\author{
G.C. Riise*, C. Kjellström**, W. Ryd+, H. Scherstén++, F. Nilsson++, \\ G. Mårtensson*, B.A. Andersson‡
}

Inflammatory cells and activation markers in BAL during acute rejection and infection in lung transplant recipients: a prospective, longitudinal study. G.C. Riise, C. Kjellström, W. Ryd, H. Scherstén, F. Nilsson, G. Mårtensson, B.A. Andersson. CERS Journals Ltd 1997

ABSTRACT: Acute rejection of the transplanted lung is a clinical problem, since it decreases graft survival and predisposes the patient to chronic rejection and obliterative bronchiolitis (OB). In an earlier study, we had indications that eosinophil cationic protein (ECP) from activated eosinophils and hyaluronan (HYA) from fibroblasts were associated with acute pulmonary rejection. This prospective longitudinal study was designed to investigate whether molecules from activated inflammatory cells in bronchoalveolar lavage (BAL) fluid could serve as clinically useful diagnostic markers for acute rejection.

BAL fluid from 138 bronchoscopies performed in 10 single lung, four bilateral lung and five heart-lung transplant recipients were analysed. Nine patients were studied for a period of more than $1 \mathrm{yr}$ (mean 13.4 months) after surgery. Differential cell counts were made from the BAL fluid. ECP, myeloperoxidase (MPO), HYA and interleukin-8 (IL-8) were used as indirect markers for activation and attraction of esinophils, neutrophils and fibroblasts, respectively.

Fifty four episodes of acute rejection were diagnosed. Two patients developed OB. Nine episodes of bacterial infection, 13 episodes of cytomegalovirus (CMV) pneumonitis, three of Pneumocystis carinii infection and one of respiratory syncytial virus (RSV) infection were diagnosed. The mean levels of ECP, MPO, HYA and IL-8 were all higher during rejection episodes, but differences were not statistically significant compared to no rejection, when the confounding factors of time, concomitant infection, and repeated measures in the same individual had been accounted for.

We could not confirm that measurements of eosinophil cationic protein, myeloperoxidase, hyaluronan and interleukin-8 in bronchoalveolar lavage fluid can be used as diagnostic markers for acute rejection in the postoperative follow-up of lung transplant recipients.

Eur Respir J 1997; 10: 1742-1746.
*Depts of Pulmonary Medicine, **Pathology, +Cytology, Sahlgrenska University Hospital, Göteborg, and ${ }^{+}$Cardiothoracic Surgery, Sahlgrenska University Hospital, Göteborg,

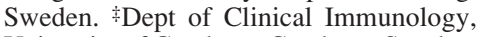
University of Göteborg, Göteborg, Sweden.

Correspondence: G.C. Riise

Dept of Pulmonary Medicine Sahlgrenska University Hospital S-413 45 Göteborg

Sweden

Keywords: Bronchiolitis

eosinophils

hyaluronan

lung transplantation

myeloperoxidase

rejection

Received: November 71996

Accepted after revision April 141997
Lung transplantation has become an accepted therapy for end-stage lung disease, and improvements in organ preservation, surgical technique, immunosuppressive treatment and infection control have contributed to increased graft and patient survival [1]. However, long-term survival is limited by chronic rejection, obliterative bronchiolitis $(\mathrm{OB})$, a severe complication with a prevalence of $30-40 \%$ in lung transplanted patients [2].

Clinically, acute rejection is diagnosed by a combination of histopathological assessment of transbronchial biopsies (TBBs) and cytological assessment of bronchoalveolar lavage (BAL) samples. Acute rejection is characterized by a perivascular lymphocytic infiltration in the parenchyma, with or without concomitant lymphocytic bronchitis/bronchiolitis [3]. Infiltration of eosinophil granulocytes can also be present [4]. A firm diagnosis requires careful exclusion of cytomegalovirus and other infections. Chronic rejection is diagnosed as therapyresistant progressive loss of lung function, with the histopathological finding of obliterative bronchiolitis in lung biopsies [5]. However, OB is easily overlooked or often not even represented in TBB [6]. Less invasive methods than TBB, as well as more sensitive predictive methods for the onset of $\mathrm{OB}$, are needed for diagnosis both of acute and chronic rejection in the transplanted lung.

One potential direction for research is the analysis of specific markers reflecting activation of inflammatory cells. Cytotoxic molecules from activated eosinophil granulocytes, such as eosinophil cationic protein (ECP), are found in acute rejection of the liver [7], and eosinophil major basic protein (MBP) in rejection of the kidney [8]. Hyaluronan (HYA), a large polysaccharide considered to reflect fibroblast activation, is increased 
during acute rejection of transplanted solid organs and is associated with interstitial oedema of the graft $[9,10]$. In an earlier retrospective study, we found eosinophil and fibroblast activation to be associated with acute rejection of pulmonary allografts [11].

The present study was designed to prospectively investigate the pattern of inflammatory cells, as well as their corresponding activation markers, in BAL fluid from lung transplanted patients over time. The aim of the study was to investigate whether any of these variables were associated with acute rejection, and if they could be used as markers to monitor this process.

\section{Methods}

\section{Subjects}

Nineteen consecutive patients undergoing single lung $(n=10)$, bilateral lung $(n=4)$, or heart lung $(n=5)$ transplantation were studied during a period from September 1994 to February 1996 (18 months). One patient underwent single lung retransplantation early in the postoperative period. Patient characteristics are presented in table 1 .

Donors and recipients were matched for cytomegalovirus (CMV) serological status. All organs were harvested in a similar fashion. Surgical procedures and immunosuppression therapy were performed as described previously $[11,12]$. Episodes of acute rejection were treated with methylprednisolone ( $1 \mathrm{gm}$ i.v.) for 3 days, and no rejection episode was resistant to steroid treatment during the time of the study.

The study design was approved by the Ethics Committee of University of Göteborg, and all subjects gave their consent after written and oral information.

\section{Postoperative follow-up}

Surveillance bronchoscopy with TBB and BAL were performed according to protocol at 2, 4, 8 and 12 weeks, and at 6,9 and 12 months after surgery. Additional TBB and BAL were performed approximately 4 weeks after augmented immunosuppressive treatment of rejection episodes, and whenever indicated by clinical parameters, such as dyspnoea, hypoxaemia, decline in forced expiratory volume in one second (FEV1) values, radio-

Table 1. - Clinical data of transplanted patients

\begin{tabular}{|c|c|c|c|c|}
\hline $\begin{array}{l}\text { Preoperative } \\
\text { diagnosis }\end{array}$ & $\begin{array}{c}\text { Pts } \\
\mathrm{n}\end{array}$ & $\begin{array}{l}\text { Sex } \\
\text { F/M }\end{array}$ & $\begin{array}{l}\text { Surgical } \\
\text { procedure }\end{array}$ & $\begin{array}{l}\text { Age } \ddagger \\
\text { yrs }\end{array}$ \\
\hline $\begin{array}{l}\text { Emphysematous } \\
\text { disease }\end{array}$ & 9 & $6 / 3$ & Single lung & $48(43-53)$ \\
\hline $\begin{array}{l}\text { Idiopathic } \\
\text { pulmonary fibrosis }\end{array}$ & 1 & $1 / 0$ & Single lung & 51 \\
\hline $\begin{array}{l}\text { Eisenmenger's } \\
\text { syndrome }\end{array}$ & 3 & $1 / 2$ & Heart-lung & $31(19-40)$ \\
\hline Primary pulmonary & 3 & $1 / 2$ & Bilateral lung & $33(25-43)$ \\
\hline hypertension & 2 & $1 / 1$ & Heart-lung & $33(21-44)$ \\
\hline Cystic fibrosis & 1 & $0 / 1$ & Bilateral lung & 25 \\
\hline
\end{tabular}

\$: mean, and range in parenthesis. Pts: patients; F: female; M: male. graphic infiltrate or unexplained fever. Fibreoptic bronchoscopy was performed transorally with local anaesthesia and intravenous propofol sedation. Supplemental $100 \%$ oxygen was delivered nasally at a rate of 4-5 $\mathrm{L} \cdot \mathrm{min}^{-1}$, with blood oxygen saturation continually monitored with an Ohmeda pulse oximeter (Ohmeda, Louisville, KY, USA).

The histopathological diagnosis of rejection was based on assessment of TBB and BAL samples. The evaluation of acute rejections followed the recommendations of the Lung Rejection Study Group of the International Society for Heart and Lung Transplantation (ISHLT) [3], and chronic rejection with obliterative bronchiolitis according to the grading system established by "a working formulation for the standardization of nomenclature and for clinical staging of chronic dysfunction in lung allografts" [5].

BAL analysis included direct microscopy for CMV inclusion bodies, Pneumocystis carinii (PCP), fungi and mycobacteria. In addition, immunocytochemistry techniques for PCP, CMV, and Legionella pneumophila in BAL and/or TBB were applied routinely. Cultures for bacteria, including legionella and mycobacteria, fungi and viruses were performed, and presence of CMV and respiratory syncytial virus (RSV) genome was investigated by polymerase chain reaction (PCR) amplification. Diagnosis of CMV pneumonitis was based on histopathological changes of alveolitis in TBB, together with presence of inclusion bodies in TBB and BAL samples. Diagnosis of bacterial infection was based on presence of significant bacterial growth in BAL sample $\left(>10^{5}\right.$ colony-forming units $\left.(\mathrm{cfu}) \cdot \mathrm{mL}^{-1}\right)$. Diagnosis of PCP was based on demonstration of the organism by silver-staining of TBB and BAL samples.

\section{Collection of samples}

All bronchoscopies were performed between 08.30 and $10.30 \mathrm{~h}$. BAL was performed by infusion of $8 \times 20$ $\mathrm{mL}$ warmed sterile pyrogen-free phosphate-buffered saline (PBS) solution into a segmental middle lobe or lingula bronchus, with the bronchoscope in a wedged position. The fluid was aspirated after each $80 \mathrm{~mL}$ infusion, collected in a sterile siliconized container, and immediately transported on ice to the laboratory. BAL recovery was measured and the fluid filtered through sterile gauze. A total cell count was performed on neat samples using a haemocytometer, and cell viability assessed by trypan blue exclusion. Cellular components were sedimented by centrifugation at $4^{\circ} \mathrm{C}, 500 \times \mathrm{g}$ for 10 min, and the supernatant removed and frozen at $-70^{\circ} \mathrm{C}$. Before later analysis of inflammatory markers, an additional 10 min centrifugation at $10,000 \times \mathrm{g}$ was performed.

Cytocentrifuge slides (Shandon Southern Products Ltd, Runcorn, UK) were made from $100 \mu \mathrm{L}$ aliquots of the resuspended cell pellet. Slides were immediately fixed in $96 \%$ alcohol and stained with May-Grünwald Giemsa for later identification of cell types on a morphological basis. Percentages of eosinophil granulocytes, polymorphonuclear granulocytes, macrophages and lymphocytes were calculated by counting 200 cells using a standard light microscope. All samples were analysed in a blinded manner. 
TBB were taken after BAL. At least five macroscopically adequate biopsy specimens were obtained under fluoroscopic guidance from different sites within one lung using alligator forceps, immediately placed in $10 \%$ buffered formalin and sent for histopathological analysis.

\section{Analysis of inflammatory markers}

Radioimmunoassay analysis of ECP (Pharmacia Diagnostics AB, Uppsala, Sweden), MPO (Pharmacia Diagnostics AB), hyaluronan (Pharmacia Diagnostics AB), IL-8 (Biosource International, Camarillo, USA), and albumin in BAL fluid were performed according to the instructions of the manufacturers. The intercoefficients and intracoefficients of variation of the radioimmunoassays used in the study have been investigated and accounted for in the assay instructions issued by the manufacturers.

\section{Statistical evaluation}

Results are expressed as arithmetic mean and standard deviation (SD), or illustrated graphically as box plots displaying the 10 th, 25th, 50th, 75th and 90th percentiles of a variable. For calculation of possible covariation between the variables studied, the longitudinal time factor as well as the registration of repeated measures in the same subject were adjusted for by use of random coefficient regression analysis [13]. The analysis allowed separate evaluation of the impact of rejection and infection, respectively, on the variables studied. A p-value of less than 0.05 was considered statistically significant.

\section{Results}

Transbronchial biopsies and BAL fluid were obtained from a total of 138 bronchoscopies, of which 44 were diagnostic ("emergency") and 94 protocol ("elective").

Nine patients were studied for a period of more than $1 \mathrm{yr}$ (mean 13.4 months), eight patients between 6 and 12 months (mean 8.0 months), and two patients 5.0 months after surgery.

\section{Rejection}

There were 54 histopathologically diagnosed acute rejection episodes, of which 40 were minimal (A1), 10 mild (A2), and four of moderate (A3) character. No episode of severe (A4) rejection was diagnosed. Two patients developed histopathological changes suggestive of chronic rejection with obliterative bronchiolitis (class $1 \mathrm{~b}$ and $2 \mathrm{~b}$ ). Thirty three samples were excluded: 7 samples with histological changes of reperfusion injury in the early post-operative period; 8 samples with changes of nonspecific alveolitis; 5 samples with too scarce biopsy material; and 13 samples with concomitant CMV infection making diagnosis of rejection uncertain.

During acute rejection episodes (infection excluded), BAL volume recovery was significantly increased $(p<0.05)$ compared to no rejection (table 2). For cell viability, cell concentration, BAL differential cell counts and albumin, no statistically significant differences were found.
Table 2. - BAL variables in relation to presence or absence of rejection (infection excluded)

\begin{tabular}{|c|c|c|c|c|}
\hline & \multicolumn{4}{|c|}{ Basic BAL variables } \\
\hline & $\begin{array}{l}\text { Volume } \\
\text { return } \\
\%\end{array}$ & $\begin{array}{l}\text { Cell } \\
\text { variability } \\
\% \quad 10^{6}\end{array}$ & $\begin{array}{l}\text { Cell } \\
\text { conc } \\
\text { cells } \cdot \mathrm{mL}^{-1}\end{array}$ & $\begin{array}{l}\text { Albumin } \\
1 \mathrm{mg} \cdot \mathrm{mL}^{-1}\end{array}$ \\
\hline Rejection $(n=54)$ & $58 *(12)$ & $78(12)$ & $0.5(1.0) 8$ & $89.9(88.7)$ \\
\hline \multirow[t]{3}{*}{ No rejection $(\mathrm{n}=58)$} & $54 \quad(11)$ & $78 \quad(8)$ & $0.3(0.2) 6$ & $66.5(66.9)$ \\
\hline & \multicolumn{4}{|c|}{ Differential cell count } \\
\hline & $\begin{array}{c}\text { Neutro- } \\
\text { phils } \\
\%\end{array}$ & $\begin{array}{c}\text { Eosino- } \\
\text { phils } \\
\%\end{array}$ & $\begin{array}{c}\text { Lympho- } \\
\text { cytes } \\
\%\end{array}$ & $\begin{array}{c}\text { Macro- } \\
\text { phages } \\
\%\end{array}$ \\
\hline Rejection $(n=54)$ & $20(24)$ & $0.3(1.3)$ & $9(8)$ & $67 \quad(24)$ \\
\hline No rejection $(\mathrm{n}=58)$ & 12 (19) & $0.2(0.5)$ & $6(6)$ & $79 \quad(20)$ \\
\hline
\end{tabular}

Values are presented as mean, and SD in parenthesis. BAL: bronchoalveolar lavage; conc: concentration. *: $\mathrm{p}<0.05$, compared to no rejection.

\section{Infection}

Nine episodes of bacterial infection, 13 episodes of CMV pneumonitis, three of Pneumocystis carinii infection and one of RSV infection were diagnosed. All were treated adequately. BAL volume recovery, cell viability, cell concentration and albumin did not differ significantly between different infections, or compared to noninfectious episodes (data not shown). BAL differential cell counts showed significantly increased percentages of polymorphonuclear granulocytes during bacterial infection compared to noninfection $(\mathrm{p}<0.01)$ (table 3$)$. No other significant differences were found when BAL cell differentials and type of infection were compared.

\section{Inflammatory markers in BAL}

The mean levels of ECP $\left(14.4 \mu \mathrm{g} \cdot \mathrm{L}^{-1}\right)$, MPO (994 $\left.\mu \mathrm{g} \cdot \mathrm{L}^{-1}\right)$, HYA $\left(107 \mu \mathrm{g} \cdot \mathrm{L}^{-1}\right)$, and IL-8 (199 $\left.\mathrm{ng} \cdot \mathrm{L}^{-1}\right)$ were all higher when rejection episodes were compared to no rejection (ECP $7.0 \mu \mathrm{g} \cdot \mathrm{L}^{-1}$, MPO $267 \mu \mathrm{g} \cdot \mathrm{L}^{-1}$, HYA 92 $\mu \mathrm{g} \cdot \mathrm{L}^{-1}$, and IL-8 $170 \mathrm{ng} \cdot \mathrm{L}^{-1}$ infection excluded). However, none of these differences were statistically significant when repeated measures, time and infection had been accounted for (fig. 1), nor were any statistically significant differences in levels of inflammatory markers found

Table 3. - BAL differential cell counts in relation to type of infection, or no infection

\begin{tabular}{|c|c|c|c|c|}
\hline & \multicolumn{4}{|c|}{ Differential cell count } \\
\hline & $\begin{array}{c}\text { Neutro- } \\
\text { phils } \\
\%\end{array}$ & $\begin{array}{c}\text { Eosino- L } \\
\text { phils } \\
\%\end{array}$ & $\begin{array}{c}\text { Lympho- } \\
\text { cytes } \\
\%\end{array}$ & $\begin{array}{c}\text { Macro- } \\
\text { phages } \\
\%\end{array}$ \\
\hline No infection $(n=112)$ & (21) & $0.3(1.0)$ & $7 \quad(8)$ & $73(22)$ \\
\hline Bacteria $(n=9)$ & $44 * *(31)$ & $0.1(0.3)$ & 3) 4 (2) & $50(30)$ \\
\hline CMV $(n=13)$ & 19 (26) & $0.2(0.5)$ & 5) $8 \quad(7)$ & $66(22)$ \\
\hline PCP $(n=3)$ & $9 \quad(12)$ & $1.0(1.0)$ & $18(20)$ & $63(26)$ \\
\hline $\operatorname{RSV}(n=1)$ & 12 & 0.5 & 7 & $90-$ \\
\hline
\end{tabular}

Values are presented as mean, and SD in parenthesis. BAL: bronchoalveolar lavage. CMV: cytomegalovirus; PCP: Pneumocystis carinii pneumonia; RSV: respiratory syncytial virus. **: $\mathrm{p}<0.01$, compared to no infection. 
a)

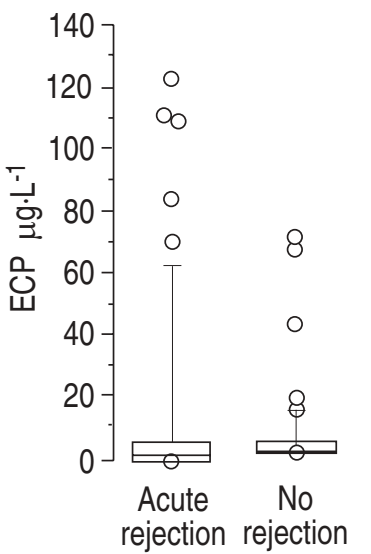

c)

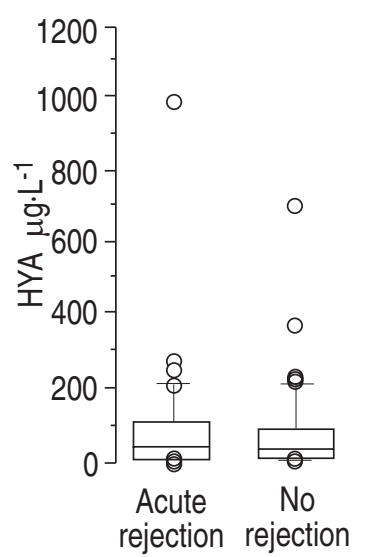

b)

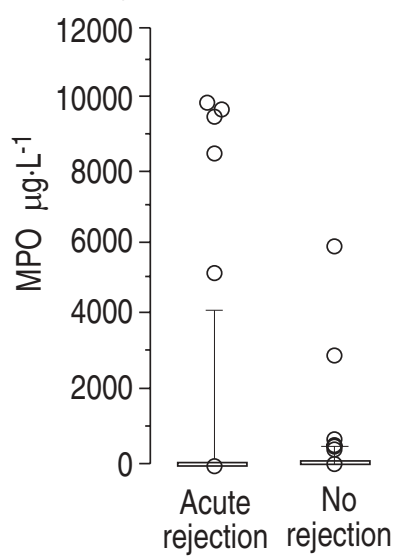

d)

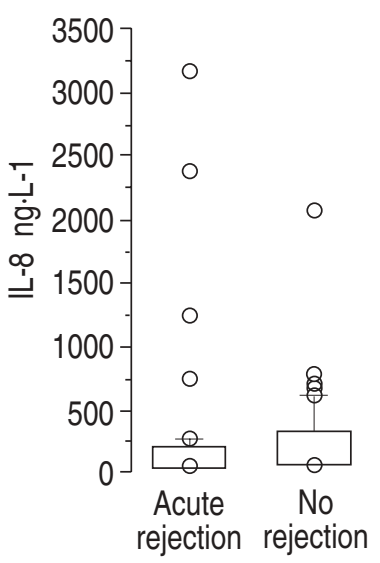

Fig. 1. - Bronchoalveolar lavage (BAL) fluid levels of: a) eosinophil cationic protein (ECP); b) myeloperoxidase (MPO); c) hyaluronan (HYA); and d) interleukin-8 (IL-8), during acute rejection ( $=54)$ and no rejection $(\mathrm{n}=58)$, respectively. Data are presented as box plots displaying the median value (50th percentile), the corresponding 10th, 25 th, 75th and 90th percentiles on either side of the median, as well as the outlying values of the variables analysed.

between the different degrees of acute rejection (data not shown).

The mean levels of ECP, MPO, HYA and IL-8 were also higher during infection, especially bacterial infection, compared to no infection (table 4). None of these differences were statistically significant when random coefficient regression analysis was performed.

Table 4. - BAL inflammatory markers in relation to type of infection, or no infection

\begin{tabular}{|c|c|c|c|c|c|c|}
\hline \multirow[b]{2}{*}{$\begin{array}{l}\text { No infection } \\
(\mathrm{n}=112)\end{array}$} & \multicolumn{2}{|r|}{$\begin{array}{l}\text { MPO } \\
\mu \mathrm{g} \cdot \mathrm{L}^{-1}\end{array}$} & $\begin{array}{c}\text { ECP } \\
\mu \mathrm{g} \cdot \mathrm{L}^{-1}\end{array}$ & $\begin{array}{c}\mathrm{HYA} \\
\mu \mathrm{g} \cdot \mathrm{L}^{-1}\end{array}$ & \multicolumn{2}{|c|}{$\begin{array}{c}\mathrm{IL}-8 \\
\mathrm{ng} \cdot \mathrm{L}^{-1}\end{array}$} \\
\hline & 652 & (2108) & 12 (28) & $172(505)$ & 277 & (781) \\
\hline $\begin{array}{c}\text { Bacteria } \\
(n=9)\end{array}$ & 2100 & (3528) & $144(318)$ & $485(508)$ & 1898 & (4395) \\
\hline CMV $(n=13)$ & 1134 & $(180$ & 14 (21) & $174(282)$ & 479 & (824) \\
\hline $\mathrm{PCP}(\mathrm{n}$ & 8 & (13) & (1) & (6) & 56 & (52) \\
\hline $\operatorname{RSV}(n=1)$ & 1972 & - & 95 & 164 & 1920 & - \\
\hline
\end{tabular}

Values are presented as mean, and SD in parenthesis. MPO: myeloperoxidase; ECP: eosinophil cationic protein; HYA: hyaluronan; IL-8: interleukin-8. For further definitions see legend to table 3 .

\section{Discussion}

This prospective, longitudinal study in lung transplant recipients shows that activation of the inflammatory cells eosinophils, neutrophils and fibroblasts, assessed by ECP, MPO and HYA in BAL fluid, respectively, is increased during acute rejection of the allograft. However, the differences were not statistically significant when the confounding factors of time, concomitant infection, and repeated measures in the same individual had been accounted for. To our knowledge, this is the first study to prospectively and longitudinally evaluate the clinical value of analysis of inflammatory markers during acute rejection in lung transplant recipients.

Earlier studies have reported increased eosinophil numbers as well as signs of eosinophil activation during acute kidney, liver and lung allograft rejection [8, 11, 14-16]. The eosinophil is known to release potent cytotoxic granule products associated with the cellular damage seen in a variety of inflammatory diseases, including bronchial asthma $[17,18]$. Several studies have hypothesized that the eosinophil could act as an effector-cell in the inflammation present during acute graft rejection [7, 14, 19].

Hyaluronan, a molecule with unique water-binding properties, is produced by activated fibroblasts in response to macrophage released mediators, such as tumour necrosis factor- $\alpha$ and $-\beta$ (TNF- $\alpha$ and TNF- $\beta$ ), and interleukin1 (IL-1) $[20,21]$. Increased levels of HYA are found during acute rejection in kidney, liver and lung transplants, and is associated with the interstitial oedema seen in allograft tissue [9, 10, 22].

In an earlier retrospective study based on a smaller number of patients, we showed that levels of ECP and HYA in BAL fluid appeared to reflect activation of eosinophils and fibroblasts during acute rejection [11]. Trends similar to these results were found in the present study, but no statistically significant differences could be found when consideration was taken of confounding factors. Since the majority of acute rejections in the present study were of only minimal or mild character, it is possible this could have influenced the results. However, the ratio of nonsevere degrees of acute rejection was similar to that found in our earlier study [11]. L-8, a cytokine with chemotactic effect on neutrophil granulocytes [23], produced by alveolar macrophages and respiratory epithelium [24], was also investigated. No significant differences with relation to acute rejection were found, and the longitudinal pattern of the cytokine was not continually elevated in any single patient.

In accordance with other studies [25-27], we observed considerable interindividual overlap in the basic BAL variables and cell differentials analysed. With the exception of increased BAL volume recovery during acute rejection, no significant differences could be found between the different diagnostic groups.

Over the years, several molecules have been investigated as candidates for specific markers of lung allograft rejection. So far, no clinically useful marker has been found. This could, in part, be due to the fact that in addition to the confounding influence of immunosuppressive treatment on inflammatory markers, lung transplant recipients also have a greater propensity for infectious complications than other solid organ transplants, making the interpretation of BAL data difficult. 
In the present study, maintenance immunosuppressive treatment did not differ between the patients. Infectious episodes resulted in large variations in levels of inflammatory markers, but the only significant finding was increased neutrophilia during bacterial infection. Infectious episodes were, therefore, excluded when levels of inflammatory markers were assessed in relation to rejection. In addition, all TBB samples without a clear diagnosis of rejection status were excluded.

To conclude, this prospective and longitudinal study could not prove that measurements of eosinophil cationic protein, myeloperoxidase, hyaluronan and interleukin8 in bronchoalveolar lavage fluid give clinically useful information about acute rejection in the postoperative follow-up of lung transplant recipients.

Acknowledgement: The authors are grateful for the generous support from The Swedish Heart and Lung Foundation, and the Medical Society of Göteborg that made this study possible.

\section{References}

1. Heritier F, Madden B, Hodson ME, Yacoub M. Lung allograft transplantation: indications, preoperative assessment and postoperative management. Eur Respir J 1992; 5: 1262-1278.

2. Bando K, Paradis I, Similo S, et al. Obliterative bronchiolitis after lung and heart-lung transplantation. $J$ Thoracic Cardiovasc Surg 1995; 110: 4-14.

3. Yousem SA, Berry G, Brunt E, et al. A working formulation for the standardization of nomenclature in the diagnosis of heart and lung rejection: lung rejection study group. J Heart Transplant 1990; 9: 593-601.

4. Yousem SA. Graft eosinophilia in lung transplantation. Hum Pathol 1992; 23: 1172-1177.

5. Cooper JD, Billingham M, Egan T, et al. A working formulation for the standardization of nomenclature and for clinical staging of chronic dysfunction in lung allografts. J Heart Lung Transplant 1993; 12: 713-716.

6. Kramer MR, Stoehr C, Whang JL, et al. The diagnosis of obliterative bronchiolitis after heart-lung and lung transplantation: low yield of transbronchial lung biopsy. J Heart Lung Transplant 1993; 12: 675-681.

7. Foster PF, Bhattacharyya A, Sankary HN, Coleman J, Ashmann M, Williams JW. Eosinophil cationic protein's role in human hepatic allograft rejection. Hepatology 1991; 13(6): 1117-1125.

8. Ten RM, Gleich GJ, Holley KE, Perkins JD, Torres VE. Eosinophil granule major basic protein in acute renal allograft rejection. Transplantation 1989; 47: 959-963.

9. Wells A, Larsson E, Tengblad A, et al. The localization of hyaluronan in normal and rejected human kidneys. Transplantation 1990; 50(2): 240-243.

10. Rao PN, Zeevi A, Snyder J, et al. Monitoring of acute lung rejection and infection by bronchoalveolar lavage and plasma levels of hyaluronic acid in clinical lung transplantation. J Heart Lung Transplant 1994; 13: 958-962.

11. Riise GC, Schersten H, Nilsson FN, Ryd W, Andersson
B. Activation of eosinophils and fibroblasts assessed by eosinophil cationic protein and hyaluronan in BAL: association with acute rejection in lung transplant recipients. Chest 1996; 110: 89-96.

12. Schersten H, Hedner T, McGregor CGA, et al. Increased levels of endothelin-1 in bronchoalveolar lavage fluid of patients with lung allografts. $J$ Thorac Cardiovasc Surg 1996; 111: 253-258.

13. Crowder MJ, Hand DJ. Analysis of repeated measures. London, Chapman and Hall, 1990.

14. Lautenschlager I, Willebrand Ev, Häyry P. Blood eosinophilia, steroids and rejection. Transplantation 1985; 40: 354-357.

15. Foster PF, Sankary HN, Williams JW. Study of eosinophilia and hepatic dysfunction as a predictor of rejection in human liver transplantation. Transplant Proc 1988; 20 : 676-677.

16. de Groen PC, Kephart GM, Gleich GJ, Ludwig J. The eosinophil as an effector cell of the immune response during hepatic allograft rejection. Hepatology 1994; 20(3): 654-662.

17. Venge P, Dahl R, Fredens K, Peterson CGB. Epithelial injury by human eosinophils. Am Rev Respir Dis 1988; 138: S54-S57.

18. Bousquet J, Chanez P, Lacoste JY, et al. Eosinophilic inflammation in asthma. $N$ Engl J Med 1990; 323: 1033-1039.

19. Almirall J, Campistol JM, Sole M, Andreu J, Revert L. Blood and graft eosinophilia as a rejection index in kidney transplant. Nephron 1993; 65(2): 304-309.

20. Butler DM, Vitti GF, Leizer T, Hamilton JA. Stimulation of hyaluronic acid levels of human synovial fibroblasts by recombinant human TNF- $\alpha$, TNF- $\beta$, IL- $1 \alpha$ and IL13. Arthritis Rheum 1988; 31: 1281-1289.

21. Wells A, Klareskog L, Lindblad S, Laurent T. Correlation between increased hyaluronan localized in arthritic synovium and the presence of proliferating cells: a role for macrophage-derived factors. Arthritis Rheum 1992; 35: 391-396.

22. Hällgren R, Gerdin B, Tengblad A, Tufveson G. Accumulation of hyaluronan (hyaluronic acid) in myocardial interstitial tissue parallels development of transplantation edema in heart allografts in rats. $J$ Clin Invest 1990; 85(3): 668-673.

23. Richman-Eisenstat JBY, Jorens PG, Hebert CA, Ueki I, Nadel JA. Interleukin-8: an important chemoattractant in sputum of patients with chronic inflammatory airway diseases. Am J Physiol 1993; 264: L413-L418.

24. Baggiolini M, Walz A, Kunkel SL. Neutrophil-activating peptide-1, interleukin-8, a novel cytokine that activates neutrophils. J Clin Invest 1989; 84: 1045-1049.

25. Clelland C, Higenbottam T, Stewart S, et al. Bronchoalveolar lavage and transbronchial lung biopsy during acute rejection and infection in heart-lung transplant patients. Am Rev Respir Dis 1993; 147: 1386-1392.

26. Whitehead BF, Stoehr C, Wu CJ, et al. Cytokine gene expression in human lung transplant recipients. Transplantation 1993; 56: 956-961.

27. Baz MA, Tapson VF, Roggli VL, Trigt PV, Piantadosi CA. Glutathione depletion in epithelial lining fluid of lung allograft patients. Am J Respir Crit Care Med 1996; 153: 742-746. 